\title{
Consumo e digestibilidade de silagens de capim-elefante com diferentes níveis de subproduto da agroindústria da acerola ${ }^{1}$
}

\author{
Intake and digestibilit of elefhant grass silages with the diferent levels of acerola \\ industry by-product
}

\author{
Ana Cristina Holanda Ferreira ${ }^{2 *}$, José Neuman Miranda Neiva ${ }^{3}$, Norberto Mario Rodriguez ${ }^{4}$, Fernando César \\ Ferraz Lopes 5 e Raimundo Nonato Braga Lôbo ${ }^{6}$
}

\begin{abstract}
Resumo - Foi objetivo deste trabalho avaliar o consumo e digestibilidade da MS e nutrientes. de silagens de capim-elefante (CE) contendo subproduto do processamento da acerola desidratada (SACD). Utilizaram-se 20 ovinos machos nãocastrados, distribuídos em delineamento inteiramente casualizado, com cinco níveis de SACD na silagem $(0 ; 3,5 ; 7 ; 10,5$ e $14 \%$ da matéria seca) e quatro repetições. Estimaram-se os consumos de matéria seca (MS), celulose, hemicelulose, proteína bruta (PB), fibra em detergente neutro (FDN), fibra em detergente ácido (FDA), bem como os consumos de matéria seca (MSD), proteína bruta (PBD), fibra em detergente neutro (FDND) e energia digestível (ED). Foram avaliados também as digestibilidades da MS, PB, FDN, FDA, celulose, hemicelulose e EB, e o balanço de nitrogênio (BN). A adição de SACD, não influenciou o consumo de MS, FDN e FDA em g animal ${ }^{-1}$ dia $^{-1}$ e g UTM ${ }^{-1}$ (unidade de tamanho metabólico $=\mathrm{PV}^{0,75}$ ), MSD, FDND em g animal ${ }^{-1}$ dia $^{-1}$ e ED $\left(0,86 \mathrm{Mcal} \mathrm{dia}^{-1}\right)$. Contudo, a adição de $1 \%$ do SACD na ensilagem do capim-elefante resultou em aumento de 1,91 e 0,04 g nos consumos diários de $\mathrm{PB}$ e PBD, respectivamente. Com a adição do SACD, não houve alterações na digestibilidade da MS (43\%), PB (36,4\%), FDN (44,8\%) e BN $\left(0,22 \mathrm{~g} \mathrm{dia}^{-1}\right)$ das silagens. Entretanto, o BN atingiu valores positivos quando foram adicionados 10,5 e 14\% do SACD à dieta. O subproduto da acerola desidratado pode ser adicionado em níveis de até $14 \%$ da matéria natural na ensilagem de capim-elefante, pois não compromete nem o consumo nem a digestibilidade dos nutrientes em ovinos.
\end{abstract}

Palavras-chave - Capim-elefante. Silagem. Acerola.

\begin{abstract}
The present study aimed to determine de nutritional value of mixed elephant grass silages and increasing levels of dehydrated acerola industry by-product (PAC). Five PAC levels $(0 ; 3.5 ; 7.0 ; 10.5$ and $14 \%)$ were evaluated in a digestibility trial with 20 male non-castrated sheep in a randomized experimental design of five treatments (PAC levels) and four replications per treatment (sheep). Intake and digestibility of dry matter (DM), crude protein (CP), neutral detergent fiber (NDF), acid detergent fiber (ADF), cellulose (CEL), hemicelulose (HCEL) and energy digestible as well as nitrogen balance were determined. The addition of PAC, didn't influence the consumption of DM, NDF, ADF, DDM and DNDF. However, the addition of $1 \%$ PAC in the silage of elephant grass resulted in increase of $1.91 \mathrm{~g}$ and $0.04 \mathrm{~g}$ in the daily consumptions of CP and DCP, respectively. With the addition of PAC, there were no alterations in the digestibility of DM (43\%), CP (36.4\%), NDF (44.8\%) and in nitrogen balance $(0.22 \mathrm{~g})$ of the silages. However, nitrogen balance reached positive values when 10.5 and $14 \%$ of PAC were added to the silage. The by-product of dehydrated acerola may be added in levels of up to $14 \%$ of the natural matter in the silage of elephant grass, because it doesn't affect the intake and digestibility of the nutrients by sheep.
\end{abstract}

Key words - Elephant grass. Silage. Acerola.

\footnotetext{
* Autor para correspondência

${ }^{1}$ Recebido para publicação em 29/12/2009; aprovado em 08/11/2010

Pesquisa financiada pelo PROCAD-Capes, parte da tese de doutorado do primeiro autor apresentada à UFMG para obtenção do grau de Doutora em Ciência Animal

${ }^{2}$ Escola de Medicina Veterinária e Zootecnia,UFT, BR 153, Km 112, Zona Rural, Caixa Postal 132, Araguaina-TO, Brasil, 77.804-970, anacristinahf@ hotmail.com

${ }^{3}$ Escola de Medicina Veterinária e Zootecnia, UFT, Araguaina-TO, Brasil, araguaia2007@gmail.com

${ }^{4}$ Escola de Veterinária, UFMG, Belo Horizonte-MG, Brasil, norberto@vet.ufmg.br

${ }^{5}$ Embrapa-Gado de Leite, Juiz de Fota-MG, Brasil, fernando@cnpgl.embrapa.br

${ }^{6}$ Embrapa-Caprinos, Sobral-CE, Brasil, lobo@cnpc.embrapa.br
} 


\section{Introdução}

A produção de silagem constitui uma das principais técnicas de conservação de volumosos. Dentre as gramíneas forrageiras tropicais, o capim-elefante (Pennisetum purpureum, Schum) tem se destacado em diversas pesquisas realizadas no país, principalmente por apresentar elevada produção de forragem por unidade de área e pelo equilíbrio nutritivo. Queiroz Filho et al., (2000) avaliando épocas de corte do capim-elefante cultivar Roxo observaram produções de 19,5 e 25,7 t ha-1 de MS, 13,8 e 8,6 $\mathrm{t} \mathrm{ha}^{-1}$ de PB e porcentagens de FDN de 65,7 e 71,3 para cortes efetuados com 40 e 60 dias, respectivamente. Entretanto, o alto teor de umidade (75 a $80 \%)$ e baixa concentração de carboidratos solúveis $(<15 \%$ MS) no momento ideal para o corte da planta, têm restringido o adequado processo fermentativo, dificultando a confecção de silagens de boa qualidade produzidas a partir do capimelefante (NEIVA; VOLTOLINI, 2006). Assim, para que a massa ensilada seja conservada eficientemente é necessário que a planta forrageira apresente um conteúdo de matéria seca entre 28 e $34 \%$, teor de carboidrato solúvel superior a $8 \%$ na MS e teores de nitrogênio amoniacal, como porcentagem do nitrogênio total, menor que $15 \%$ (MCCULLOUGH, 1977; McDONALD, 1981).

Assim, com o intuito de minimizar estes fatores, têm-se comumente adicionado no momento da ensilagem produtos ricos em matéria seca e/ou carboidratos solúveis. Dentre eles, pode-se destacar os resíduos regionais da agroindústria, como os do caju, abacaxi, maracujá, manga, graviola, acerola e goiaba (CÂNDIDO et al., 2007; CYSNE et al., 2006; FERREIRA et al., 2004; 2007; 2009a; GONÇALVES et al., 2004; SÁ et al., 2007).

A acerola (Malpighia glabra D.C.), pelo seu indubitável potencial como fonte natural de vitamina $\mathrm{C}$ e sua grande capacidade de aproveitamento industrial, tem atraído o interesse dos fruticultores e passou a ter importância econômica em várias regiões do Brasil, com plantios comerciais em praticamente todos os Estados, tornando o país o maior produtor consumidor e exportador de acerola no mundo (NOGUEIRA et al., 2002).

Contudo, Coelho et al., (2003) relataram que apesar da maior parte da produção de acerola encontrar-se vinculada ao setor agroindustrial, com vistas ao aproveitamento dos frutos, parte considerável não é aproveitada devido à alta perecibilidade dos frutos, estimando-se perdas de pós-colheita em $40 \%$. Conforme dados de agroindústrias, o rendimento médio da produção de resíduo com o processamento da acerola para produção de suco é de 13,3\% do total processado. Como a acerola produz de três a quatro safras por ano, podendo chegar até a seis, a oferta de resíduos é praticamente constante durante o ano, sendo esse constituído, principalmente, pela semente, polpa macerada e frutos refugados.

Quando desidratado, seu subproduto apresenta, em média, 85,7\% de matéria seca (LOUSADA JUNIOR et al., 2005; VASCONCELOS et al., 2002) e pH de 3,31 na polpa da acerola desidratada (SOARES et al., 2001). Com estes teores de matéria seca, o subproduto pode funcionar como aditivo absorvente, aumentando a pressão osmótica no meio e juntamente com seu baixo $\mathrm{pH}$, auxiliar na prevenção do crescimento das bactérias do gênero Clostridium.

Gonçalves et al., (2004) estudaram a inclusão do subproduto da acerola em silagens de capim-elefante e observaram elevação nos teores de matéria seca (MS) e de proteína bruta (PB) das silagens. Com a adição de $15 \%$ do subproduto da acerola a silagem atingiu o teor de $30 \%$ de MS. Os valores de $\mathrm{pH}$ reduziram linearmente com a adição do subproduto, alcançando valores de 3,58 nas silagens com $20 \%$ do subproduto da acerola desidratado.

Porém, numa avaliação do valor nutritivo dos alimentos, a simples determinação da composição química não é suficiente, devendo ser considerado também efeitos de consumo e digestibilidade.

Realizou-se este experimento para avaliar o efeito da inclusão de níveis de subproduto da acerola desidratada na silagem de capim-elefante sobre o consumo e a digestibilidade da matéria seca e nutrientes e sobre o balanço de nitrogênio de ovinos.

\section{Material e métodos}

O experimento foi conduzido no Núcleo de Pesquisas em Forragicultura do Departamento de Zootecnia do Centro de Ciências Agrárias da Universidade Federal do Ceará (UFC), em Fortaleza, Ceará. O município de Fortaleza situa-se na Zona Litorânea, a 15,5 m de altitude, 3०43'02" de latitude Sul e 38 32'35' ' de longitude Oeste.

Estudou-se a adição de cinco níveis $(0 ; 3,5 ; 7,0 ; 10,5$ e $14 \%$ com base na matéria natural) do subproduto da acerola (Malpighia glabra) desidratado - SACD - na ensilagem do capim-elefante (Pennisetum purpureum, Schum).

Utilizou-secapim-elefantevr.mineirãoproveniente de capineira estabelecida na Fazenda Experimental do Vale do Curú, em Pentecoste, Ceará, pertencente à UFC. O capim foi cortado manualmente, aproximadamente aos 70 dias de crescimento, e processado em picadeira de forragem convencional, apresentando tamanho final médio de partículas entre 1 e $2 \mathrm{~cm}$. Posteriormente, foi misturado ao subproduto da acerola originado do processamento da fruta para extração de sucos e polpas, de agroindústrias, localizada em Mossoró (RN). 
O SACD foi composto basicamente por sementes, apresentando baixa percentagem (30 a $40 \%$ ) de frutos refugados. A desidratação foi realizada ao sol, em área cimentada, por período de $48 \mathrm{~h}$, até que atingisse 13 a $16 \%$ de umidade; O SACD foi espalhado em camadas de, aproximadamente, $7 \mathrm{~cm}$ de espessura, e revolvido pelo menos três vezes ao dia. À noite o material foi amontoado e coberto por lona, evitando o acúmulo de umidade.

A composição químico-bromatológica do capimelefante (CE) e do SACD antes da ensilagem, encontrase na Tabela 1 .

Como silos experimentais, foram utilizados tambores plásticos de $210 \mathrm{~L}$. Após a pesagem e homogeneização do capim elefante com o SACD, o material foi colocado nos silos $(126 \pm 5 \mathrm{~kg}$ de forragem, em densidade de $600 \pm 5 \mathrm{~kg} \mathrm{~m}^{-3}$ e compactado por pisoteamento de homens. Completado o enchimento, os silos foram fechados com lonas plásticas presas com ligas de borracha. A abertura dos silos foi realizada 28 dias após o enchimento.

Os dados referentes às composições químicobromatológicas das silagens de capim-elefante com níveis crescentes de adição do subproduto da acerola desidratada (SACD) estão apresentados na Tabela 2.

Para determinação do consumo de matéria seca e nutrientes, digestibilidade aparente das silagens e do balanço de nitrogênio promovida pelas mesmas aos animas, utilizaram-se 20 carneiros não-castrados, sem raça definida, com média de $28 \pm 2 \mathrm{~kg}$ de peso corporal, distribuídos em delineamento inteiramente casualisado com cinco níveis de $\operatorname{SACD}(0 ; 3,5 ; 7$;
10,5 e $14 \%$ ) e quatro repetições, considerando cada animal uma unidade experimental. Para cada animal, foi utilizada silagem de um único silo experimental. Os animais foram pesados no início, em jejum e no final do experimento, vermifugados e distribuídos por sorteio em cada nível de SACD avaliado. Os animais foram mantidos em gaiolas de metabolismo individuais dotadas de coletores e separadores de fezes e urina, de cochos e bebedouros para fornecimento do alimento, mistura mineral e água à vontade.

O experimento teve duração de 15 dias, sendo dez dias para adaptação dos animais às dietas e ao ambiente experimental e cinco para avaliação do consumo voluntário, digestibilidade aparente dos nutrientes e do balanço de nitrogênio.

As silagens foram fornecidas diariamente em dois períodos: manhã (6h30 às 7h30) e tarde (15h30 às 16h30), em quantidade calculada diariamente de acordo com o consumo do dia anterior, para permitir sobras de, aproximadamente, 15\%. Amostras de silagens (100 g) foram colhidas diariamente no momento da pesagem do alimento oferecido, durante todo o período de coletas de dados, acondicionadas em sacos plásticos identificados, e armazenadas em congelador a $-10{ }^{\circ} \mathrm{C}$. Ao final do experimento, as amostras da ração oferecida para cada animal foram descongeladas e homogeneizadas, retirando-se uma amostra de, aproximadamente, $300 \mathrm{~g}$, que foi processada (pré-secada) para posteriores análises químico-bromatólogica. As sobras foram pesadas pela manhã, antes do fornecimento da nova alimentação, e amostradas (aproximadamente, $80 \mathrm{~g}$ ) pelo mesmo procedimento descrito para dos alimentos oferecidos.

Tabela 1 - Composição químico-bromatólogica do capim-elefante (Pennisetum purpureum, Schum) e do subproduto da acerola (Malpighia glabra, Linn.) desidratado antes da ensilagem

\begin{tabular}{|c|c|c|}
\hline Nutrientes & Capim-elefante & Subproduto da acerola desidratado \\
\hline Matéria seca (\%) & 20,6 & 83,4 \\
\hline Proteína bruta ${ }^{(1)}$ & 5,1 & 11,0 \\
\hline Fibra em detergente neutro ${ }^{(1)}$ & 74,0 & 73,5 \\
\hline Fibra em detergente ácido ${ }^{(1)}$ & 40,9 & 54,9 \\
\hline Hemicelulose $^{(1)}$ & 33,1 & 18,5 \\
\hline Celulose $^{(1)}$ & 31,4 & 29,5 \\
\hline Lignina $^{(1)}$ & 13,3 & 26,5 \\
\hline $\mathrm{NIDN}^{(2)}$ & 33,9 & 30,8 \\
\hline $\operatorname{NIDA}^{(3)}$ & 11,4 & 18,4 \\
\hline Carboidratos solúveis $^{(4)}$ & 6,8 & 6,5 \\
\hline EB (Mcal kg-1 de MS) & 4,1 & 4,9 \\
\hline
\end{tabular}

${ }^{(1)}$ Em base da matéria seca (\%); (2) Nitrogênio insolúvel em detergente neutro (\% do nitrogênio total); ${ }^{(3)}$ Nitrogênio insolúvel em detergente ácido (\% do nitrogênio total); ${ }^{(4)} \mathrm{g} \mathrm{kg}^{-1}$ de matéria seca 
Tabela 2 - Composição químico-bromatológica e característica fermentativa do capim-elefante (Pennisetum purpureum, Schum) (CE) ensilado com níveis crescentes de subproduto da acerola (Malpighia glabra, Linn.) desidratada (SACD)

\begin{tabular}{lccccc}
\hline \multirow{2}{*}{ Nutrientes } & \multicolumn{5}{c}{ Níveis de adição do SACD (\%) } \\
\cline { 2 - 6 } & \multicolumn{1}{c}{3,5} & \multicolumn{1}{c}{7} & 10,5 & 14 \\
\hline Matéria seca (\%) & 19,75 & 23,21 & 24,91 & 26,83 & 30,85 \\
Matéria orgânica (\% da MS) & 85,67 & 86,46 & 87,53 & 88,31 & 90,18 \\
Proteína bruta (\% da MS) & 5,45 & 7,43 & 7,98 & 8,73 & 10,01 \\
Fibra em detergente neutro (\% da MS) & 73,04 & 73,82 & 74,90 & 75,75 & 76,25 \\
Fibra em detergente ácido (\% da MS) & 44,46 & 44,24 & 47,83 & 50,12 & 53,64 \\
Hemicelulose (\% da MS) & 28,58 & 29,57 & 27,08 & 25,63 & 22,61 \\
Celulose (\% da MS) & 31,45 & 28,76 & 30,73 & 31,38 & 29,78 \\
Lignina (\% da MS) & 13,01 & 15,48 & 17,10 & 18,73 & 23,86 \\
NIDN ${ }^{(1)}$ & 24,72 & 25,35 & 28,31 & 27,70 & 30,47 \\
NIDA ${ }^{(2)}$ & 11,83 & 13,22 & 17,80 & 18,06 & 22,07 \\
EB (Mcal kg-1 de MS); & 3,93 & 4,00 & 4,11 & 4,20 & 4,25 \\
Ácido lático (\% da MS) & 2,660 & 4,236 & 2,571 & 0,785 & 0,656 \\
Ácido acético (\% da MS) & 0,447 & 0,194 & 0,186 & 0,183 & 0,232 \\
Ácido propiônico (\% da MS) & 0,047 & 0,030 & 0,028 & 0,016 & 0,023 \\
Ácido butírico (\% da MS) & 0,074 & 0,030 & 0,013 & 0,018 & 0,123 \\
pH & 4,7 & 4,22 & 4,21 & 3,95 & 3,96 \\
N-NH $_{3}$ NT $^{-1}$ (3) & 15,95 & 10,80 & 13,00 & 6,60 & 6,97 \\
\hline
\end{tabular}

${ }^{(1)}$ Nitrogênio insolúvel em detergente neutro (\% do nitrogênio total); ${ }^{(2)}$ Nitrogênio insolúvel em detergente ácido (\% do nitrogênio total); ${ }^{(3)}$ Nitrogênio amoniacal (\% do nitrogênio total)

As fezes foram colhidas durante os cinco dias de avaliação e pesadas no período da manhã. Do total individual diário, retirou-se uma amostra de $10 \%$, que foi acondicionada em congelador a $-10{ }^{\circ} \mathrm{C}$. Ao final do experimento, as amostras referentes a cada animal foram descongeladas e homogeneizadas para retirada de, aproximadamente, $300 \mathrm{~g}$ do total de cada animal. Estas foram acondicionadas em sacos plásticos identificados e mantidos em congelador $\mathrm{a}-10{ }^{\circ} \mathrm{C}$.

Nas vasilhas coletoras de urina, adicionou-se ácido clorídrico 1:1 $(20 \mathrm{~mL})$ para evitar perdas de nitrogênio por volatilização. $\mathrm{O}$ volume total de urina produzido pelos animais foi medido pela manhã e à tarde, quando foram retiradas alíquotas de $10 \%$ do total, as quais foram acondicionadas em congelador a $-10{ }^{\circ} \mathrm{C}$ até o momento das análises de nitrogênio.

No Laboratório de Nutrição Animal do Departamento de Zootecnia da Universidade Federal de Minas Gerais, as amostras foram submetidas a présecagem em estufa de circulação forçada a $55{ }^{\circ} \mathrm{C}$ e moídas em moinho com peneira de malha de $1,0 \mathrm{~mm}$ de diâmetro, para posteriores determinações de MS, PB, FDN, FDA, CEL, LIG, EB, NIDN (\% do N total), NIDA
(\% do $\mathrm{N}$ total) para as silagens e MS, PB, FDN, FDA, CEL para sobras e fezes segundo Compêndio Brasileiro de Alimentação Animal (1998).

$\mathrm{O}$ valor de $\mathrm{pH}$ foi determinado conforme Silva e Queiroz (2002) e o teor de $\mathrm{N}^{-N_{3}}$ (\% do $\mathrm{N}$ total) foi determinado seguindo metodologia desenvolvida por Bolsen et al. (1992) e adaptada por Cândido (2000).

Para determinação dos ácidos orgânicos, foi coletado o suco das silagens utilizando-se prensa hidráulica. Coletou-se $50 \mathrm{~mL}$ de suco e colocou-se em recipientes contendo $10 \mathrm{~mL}$ de solução ortofosfórica a $25 \%$, que após tampados foram colocados em freezer a $-10^{\circ} \mathrm{C}$, para posteriores análises.

Com os valores obtidos nas análises da composição química das amostras, foram determinados os consumos de MS e PB, em g/dia e g $\mathrm{UTM}^{-1}$ (unidade de tamanho metabólico $\left.=\mathrm{PV}^{0,75}\right)$, e os consumos de FDN, FDA, hemicelulose e celulose, em $\mathrm{g} \mathrm{dia}{ }^{-1} \mathrm{e} \% \mathrm{PV}$ e o consumo de energia digestível (Mcal dia $^{-1}$ ). Determinaram-se também os coeficientes de digestibilidade dos nutrientes e da energia da dieta, bem como o balanço de nitrogênio, segundo metodologia descrita por Silva e Leão (1979). 
Para avaliação do efeito dos níveis crescentes de SACD, foram realizadas análises de variância e de regressão utilizando-se o Statistical Analyses System - SAS (1990). Na regressão, a escolha do modelo mais adequado para cada variável baseou-se na significância dos coeficientes linear e quadrático, utilizando-se o teste $\mathrm{t}$ (Student) nos níveis 1 e $5 \%$ de probabilidade, e no coeficiente de determinação. Antes dessas análises, verificaram-se as pressuposições de distribuição normal e homocedasticidade dos dados, não havendo necessidade de transformação de dados.

\section{Resultados e discussão}

Os níveis de adição de SACD na ensilagem do capim-elefante não influenciaram $(P>0,05)$ os coeficientes de digestibilidade da matéria seca, proteína bruta, fibra em detergente neutro, fibra em detergente ácido, hemicelulose, celulose e nem nos valores de energia digestível da dieta (TAB. 3).

Embora a adição do SACD tenha melhorado algumas características químicas das silagens, como por exemplo, o teor de PB (TAB. 2) tais alterações não foram suficientes para permitir melhor aproveitamento desses alimentos pelos animais. Uma possível explicação para esse fato é o elevado percentual de NIDN e NIDA que são de uso limitado pelos microrganismos ruminais (VAN SOEST; MANSON, 1991; VAN SOEST, 1994).

Destaca-se que mesmo com o aumento dos teores de NIDA as silagens com adição do SACD apresentaram, em média, elevação de 55\% na digestibilidade da PB (DPB) com relação àquelas exclusivas de capimelefante. Possivelmente, os teores mais elevados de PB encontrados nas silagens com SACD justifiquem esses aumentos percentuais. Lousada Jr. et al., (2005) avaliando o valor nutritivo de cinco subprodutos agroindustriais (abacaxi, acerola, goiaba, maracujá e melão) observaram que nem sempre subprodutos com NIDA mais elevados apresentaram menor DPB, concluindo que, os teores de PB exerceram maior influência na digestibilidade que os teores de NIDA. O subproduto do maracujá apresentou DPB $(54,4 \%)$ superior ao da goiaba $(39,5 \%)$, em razão do maior teor de PB $(12,4 \%)$ em relação ao subproduto da goiaba $(8,5 \%)$.

Os teores de lignina das silagens também aumentaram com a adição do SACD na ensilagem do capim-elefante (TAB. 2). Dietas com alto teor de lignina podem limitar o potencial de digestão dos carboidratos fibrosos. Segundo Jung e Deetz (1993) este composto pode atuar de três maneiras sobre a redução da digestibilidade da parede celular: 1) reduzindo a população de microorganismos, pelo efeito tóxico de alguns componentes da lignina (ácido cumárico) que são liberados durante a digestão da parede celular; 2) provocando impedimento físico pela ligação lignina-polissacarídeos, que limita o acesso das enzimas fibrolitícas; e 3) pela ação hidrofóbica decorrente dos polímeros de lignina, limitando a ação das enzimas hidrofílicas, cuja atividade faz-se em ambiente aquoso. Dessa forma, mesmo aumentando componentes potencialmente digestíveis pelo aumento na inclusão de SACD, também foram aumentados componentes indigestíveis o que pode ter contribuído para a não observação de alterações na digestibilidade das silagens quando avaliadas in vivo.

Assim, os baixos teores de digestibilidade dos nutrientes obtidos neste trabalho, podem ser reflexos tanto da disponibilidade do nitrogênio nas silagens, pelo

Tabela 3 - Digestibilidade dos nutrientes, valores de energia digestível, balanço de nitrogênio e coeficiente de determinação $\left(\mathrm{R}^{2}\right)$ do capim-elefante (Pennisetum purpureum, Schum) ensilado com subproduto da acerola (Malpighia glabra, Linn.) desidratado (SACD)

\begin{tabular}{|c|c|c|c|c|c|c|}
\hline \multirow{2}{*}{ Nutrientes } & \multicolumn{5}{|c|}{ Níveis de SACD (\%) } & \multirow{2}{*}{$\mathrm{R}^{2}$} \\
\hline & 0 & 3,5 & 7 & 10,5 & 14 & \\
\hline Matéria seca & 42,2 & 48,8 & 44,4 & 52,1 & 32,6 & ns \\
\hline Proteína bruta & 18,5 & 43,4 & 35,7 & 48,9 & 38,7 & ns \\
\hline Fibra em detergente neutro & 42,4 & 50,7 & 47,9 & 53,5 & 32,5 & ns \\
\hline Fibra em detergente ácido & 38,6 & 46,6 & 44,8 & 48,9 & 26,6 & ns \\
\hline Hemicelulose & 46,9 & 56,1 & 52,7 & 61,8 & 42,8 & ns \\
\hline Celulose & 52,8 & 64,4 & 65,0 & 59,6 & 31,7 & ns \\
\hline Energia digestível $^{(1)}$ & 1,62 & 1,83 & 1,83 & 2,11 & 1,22 & ns \\
\hline Balanço de nitrogênio $^{(2)}$ & $-1,82$ & 0,98 & $-0,69$ & 2,43 & 0,74 & ns \\
\hline
\end{tabular}

ns (não-significativo); ${ }^{(1)} \mathrm{Mcal} \mathrm{kg}^{-1}$ de matéria seca; ${ }^{(2)} \mathrm{g}_{\text {animal }}{ }^{-1} \mathrm{dia}^{-1}$ 
aumento do teor de NIDA, como pelo aumento dos teores de lignina das silagens com adição do SACD. Resultados semelhantes foram relatados por Ferreira (2002) que não observou efeito dos níveis de adição do bagaço de caju na ensilagem do capim-elefante sobre a digestibilidade da MS, PB, FDN, FDA e HCEL.

Lousada Junior et al., (2005) avaliando subprodutos (abacaxi, acerola, goiaba, maracujá e melão) da agroindústria em ensaios de digestibilidade observaram digestibilidades da MS, PB, FDN e FDA de 22,8; 33,2; 16,8 e $8,2 \%$, respectivamente, para o subproduto da acerola. Também como observado neste trabalho, os autores atribuíram os baixos valores de digestibilidade aos elevados níveis de NIDA, contudo eles ressaltam ainda a possível presença de tanino, funcionando como importante fator depressor da DPB, presente principalmente nos subprodutos com sementes, como a acerola. Assim os valores de digestibilidade mais elevados observados neste trabalho podem ser atribuídos ao capim-elefante, uma vez que, sua silagem apresentou valores bem maiores que os observados para o SACD exclusivo.

Não houve efeito $(\mathrm{P}>0,05)$ dos níveis crescentes de adição do SACD sobre o balanço de nitrogênio $\left(\mathrm{g} \mathrm{dia}^{-1}\right)$, conforme apresentado na Tabela 3. Contudo, constatou-se que nas silagens com 3,5; 10,5 e 14\% do SACD houve balanço de nitrogênio positivo. Possivelmente, este efeito está relacionado com o aumento no consumo de $\mathrm{PB}$ das silagens com a adição do SACD, uma vez que, a despeito do aumento dos teores de NIDA nas silagens com o incremento do SACD, registrou-se que as silagens com 3,$5 ; 7 ; 10,5$ e $14 \%$ do SACD apresentaram teores de 6,4 ; 6,$5 ; 7,1$ e $7,8 \%$ de $P B$.

$\mathrm{O} \mathrm{BN}$ negativo observado na silagem com 7\% do SACD possivelmente pode estar relacionado com os teores de nitrogênio amoniacal observado nestas silagens $(13,0 \%)$. Dentre as silagens com adição de SACD, aquela com adição de $7 \%$ foi a única que apresentou teor acima de $12 \%$ de $\mathrm{N}-\mathrm{NH}_{3} / \mathrm{NT}$ (TAB. 2), valor limite para caracterização de silagens bem preservadas e com baixa atividade proteolítica (McDONALD, 1981).

Segundo Muck (1988) a produção de ácido butírico, amônia e amina durante o processo de fermentação de silagens é fortemente relacionada à redução do consumo ad libitum de alimentos em ruminantes.

Deve ser lembrado que animais alimentados com silagens apresentam menor eficiência de retenção de nitrogênio, devido à falta de sincronização da liberação do nitrogênio não-protéico com a energia no rúmen (McDONALD, 1981; VAN SOEST, 1994).

Pelo estudo de regressão não se observou efeito $(\mathrm{P}>0,05)$ da adição do SACD na ensilagem do capim- elefante para o CMS em g dia ${ }^{-1}$ e $\mathrm{g} \mathrm{UTM}^{-1}$ (TAB. 4). De forma semelhante, foi observado por Ferreira et al., (2009b) que não observaram efeito $(\mathrm{P}>0,05)$ da adição de $7 \%$ do SACD em ensaio de desempenho produtivo de ovinos alimentados com silagens de capim-elefante contendo subprodutos do processamento de frutas.

Possivelmente, os elevados teores de componentes fibrosos e mais especificamente da lignina podem ter limitado os benefícios advindos da elevação dos teores de MS (TAB. 1). Esta suposição é respaldada pelo trabalho de Lousada Junior et al., (2005) que avaliaram o fornecimento dos subprodutos na alimentação de ovinos, e observaram que o menor CMS foi registrado quando foi fornecido o subproduto da acerola $\left(500,3 \mathrm{~g} \mathrm{dia}^{-1}\right.$ e 34,2 $\mathrm{g} \mathrm{UTM}^{-1}$ ). Segundo os autores, o menor CMS foi atribuído ao elevado teor de lignina encontrado no subproduto.

Van Soest (1994) explicou que a eficiência no consumo de alimentos pelos ruminantes, pode ser atribuída ao fornecimento adequado de $\mathrm{N}$ para o animal; do processo fermentativo ruminal e da habilidade de remoção de resíduos indigeríveis do rúmen. Segundo Wilkins (1969) dietas com alto teor de parede celular restringe o ataque das enzimas digestivas e, conseqüentemente, diminuem a digestibilidade da fibra, aumentando o período de retenção dos sólidos no rúmen (MINSON; WILSON, 1994) e levando à redução do consumo.

Contudo, mesmo não ocorrendo efeito significativo dos níveis de adição do SACD sobre o CMS, as silagens com adição do subproduto apresentaram, em média, consumo de 35 a $40 \%$ maior que a silagem exclusiva de capimelefante. Este fato pode estar relacionado ao baixo teor de MS, associado ao elevado $\mathrm{pH}(4,7)$ e às concentrações de nitrogênio amoniacal $(15,96 \%)$ registradas, que podem ter contribuído para a ocorrência de fermentação inadequada nas silagens exclusivas de capim-elefante. Muck (1988) comentou que, além da perda de MS e energia que acomete silagens com alta umidade, o ponto principal a reduzir o consumo voluntário de silagens pelos ruminantes, seria a produção de ácido butírico, amônia e aminas.

Além do mais, Waldo (1986) explicou que a quantidade de volumoso presente na dieta, associada os maiores conteúdos de água, determinou o espaço ocupado no rúmen, podendo vir a limitar o consumo pelo efeito da distensão ruminal.

Já Neiva et al., (2006) trabalhando com silagens de capim-elefante com níveis de adição do subproduto do maracujá desidratado e por Ferreira et al., (2009a) com níveis de inclusão do subproduto do abacaxi desidratado também na ensilagem do capim-elefante observaram aumento linear no CMS, com a adição dos respectivos subprodutos desidratados. Tal fato, pode estar relacionado 
Tabela 4 - Equações de regressão e coeficiente de determinação $\left(\mathrm{R}^{2}\right)$ para os consumos de nutrientes e energia digestível de silagens de capim-elefante (Pennisetum purpureum, Schum) contendo subproduto da acerola (Malpighia glabra, Linn.) desidratada

\begin{tabular}{|c|c|c|c|c|c|c|c|}
\hline & \multicolumn{5}{|c|}{ Níveis de adição do SACD (\%) } & \multirow{2}{*}{ Equações } & \multirow{2}{*}{$\mathrm{R}^{2}$} \\
\hline & 0 & 3,5 & 7 & 10,5 & 14 & & \\
\hline \multicolumn{8}{|c|}{ Matéria seca } \\
\hline g animal ${ }^{-1}$ dia $^{-1}$ & 395,6 & 554,4 & 425,7 & 534,9 & 497,3 & $\hat{\mathrm{Y}}=481,58$ & ns \\
\hline $\mathrm{g} \mathrm{UTM}^{-1}$ & 37,44 & 50,53 & 40,85 & 49,17 & 46,11 & $\hat{\mathrm{Y}}=44,82$ & ns \\
\hline \multicolumn{8}{|c|}{ Proteína bruta } \\
\hline g animal ${ }^{-1} \mathrm{dia}^{-1}$ & 23,03 & 42,99 & 36,72 & 49,04 & 53,56 & $\hat{\mathrm{Y}}=27+1,91 \mathrm{x}$ & $0,31^{*}$ \\
\hline $\mathrm{g} \mathrm{UTM}^{-1}$ & 2,19 & 3,94 & 3,52 & 4,51 & 4,95 & $\hat{Y}=2,60+0,17 x$ & $0,34 *$ \\
\hline \multicolumn{8}{|c|}{ Fibra em detergente neutro } \\
\hline g animal ${ }^{-1}$ dia $^{-1}$ & 283,4 & 403,0 & 322,8 & 405,7 & 371,8 & $\hat{\mathrm{Y}}=357,34$ & ns \\
\hline$\% \mathrm{PV}$ & 1,22 & 1,66 & 1,42 & 1,68 & 1,56 & $\hat{Y}=1,5$ & ns \\
\hline \multicolumn{8}{|c|}{ Fibra em detergente ácido } \\
\hline $\mathrm{g}_{\text {animal }}{ }^{-1} \mathrm{dia}^{-1}$ & 169,2 & 241,5 & 203,1 & 265,1 & 260,1 & $\hat{\mathrm{Y}}=227,8$ & ns \\
\hline$\% \mathrm{PV}$ & 0,73 & 0,99 & 0,89 & 1,10 & 1,09 & $\hat{Y}=0,96$ & $\mathrm{~ns}$ \\
\hline \multicolumn{8}{|c|}{ Hemicelulose } \\
\hline $\mathrm{g}$ animal $^{-1}$ dia $^{-1}$ & 114,2 & 161,5 & 119,6 & 140,6 & 111,6 & $\hat{\mathrm{Y}}=129,5$ & ns \\
\hline$\% \mathrm{PV}$ & 0,49 & 0,67 & 0,52 & 0,58 & 0,47 & $\hat{\mathrm{Y}}=0,55$ & ns \\
\hline \multicolumn{8}{|c|}{ Celulose } \\
\hline g animal ${ }^{-1}$ dia $^{-1}$ & 113,9 & 147,5 & 123,0 & 157,0 & 127,6 & $\hat{\mathrm{Y}}=133,8$ & ns \\
\hline$\% \mathrm{PV}$ & 0,49 & 0,60 & 0,54 & 0,65 & 0,54 & $\hat{Y}=0,56$ & ns \\
\hline \multicolumn{8}{|c|}{ Matéria seca digestível } \\
\hline $\mathrm{g}$ animal $^{-1}$ dia $^{-1}$ & 165,0 & 277,2 & 196,61 & 307,2 & 162,89 & $\hat{Y}=221,8$ & ns \\
\hline \multicolumn{8}{|c|}{ Proteína bruta digestível } \\
\hline g animal ${ }^{-1}$ dia $^{-1}$ & 4,68 & 19,06 & 12,72 & 26,33 & 21,06 & $\hat{\mathrm{Y}}=0,79+0,04 \mathrm{x}$ & $0,28 *$ \\
\hline \multicolumn{8}{|c|}{ Fibra em detergente neutro digestível } \\
\hline g animal ${ }^{-1}$ dia $^{-1}$ & 118,1 & 208,5 & 149,49 & 238,8 & 116,46 & $\hat{\mathrm{Y}}=166,3$ & $\mathrm{~ns}$ \\
\hline \multicolumn{8}{|c|}{ Energia digestível } \\
\hline Mcal/dia & 0,63 & 1,04 & 0,79 & 1,24 & 0,61 & $\hat{\mathrm{Y}}=0,86$ & $\mathrm{~ns}$ \\
\hline
\end{tabular}

${ }^{\text {ns }}$ (não-significativo); * (significativo a $1 \%$ de probabilidade)

com o menor teor dos componentes fibrosos nestes materiais, 49 e $24 \%$ de FDN, respectivamente.

Os níveis de SACD apresentaram efeito linear $(\mathrm{P}<0,01)$ sobre o consumo de proteína bruta $(\mathrm{CPB})$ das silagens. Para cada $1 \%$ de inclusão do $\mathrm{SACD}$, o CPB aumentou em 1,91 $\mathrm{g}$ animal ${ }^{-1} \mathrm{dia}^{-1}$, enquanto, para o consumo expresso em $\mathrm{g} \mathrm{UTM}^{-1}$, o aumento foi de $0,17 \mathrm{~g}$ para cada $1 \%$ de inclusão do SACD. Desta forma, a variação no $\mathrm{CPB}$ pode chegar a $100 \%$, ao comparar-se a silagem com $14 \%$ de inclusão de SACD com aquela confeccionada exclusivamente de capim-elefante. Este aumento no $\mathrm{CPB}$ reforça a possibilidade de suprimento mínimo de nitrogênio aos microrganismos do rúmen fornecido pela adição do SACD na ensilagem do capim-elefante.

Aumento linear no CPB também foi observado por Ferreira (2002) e Neiva et al., (2006) que trabalharam com ovinos recebendo níveis crescentes de adição dos subprodutos do caju e do maracujá na silagem do capimelefante, respectivamente. Lousada Junior et al., (2005) forneceram o SACD como alimento exclusivo para ovinos e registraram CPB de 55,5 $\mathrm{g}$ animal $^{-1} \mathrm{dia}^{-1}$ e 3,8 $\mathrm{g} \mathrm{UTM}^{-1}$, o que mostra o maior potencial de fornecimento de PB desse subproduto em comparação ao capim-elefante em estádio de desenvolvimento mais avançado. 
Conforme apresentado na Tabela 4, adição do SACD na ensilagem do capim-elefante não influenciou $(\mathrm{P}>0,05)$ o consumo de fibra em detergente neutro (CFDN), fibra em detergente ácido (CFDA), hemicelulose (CHCEL) e celulose (CCEL) (g animal ${ }^{-1} \mathrm{dia}^{-1}$ e \%PV). Os consumos dos constituintes da parede celular das silagens (FDN, FDA, HCEL, CEL) foram determinados em função do CMS, que não foi alterado, e de suas concentrações na MS das silagens, que foram bastante próximas. Desta forma, a ausência de efeito nas variáveis avaliadas é justificável pela semelhança nos teores de componentes da parede celular entre as silagens avaliadas, e nos valores de CMS proporcionados.

Os valores de ingestão de MS, FDN e energia digestível (TAB. 4) não sofreram influência $(\mathrm{P}>0,05)$ dos níveis de adição do SACD na ensilagem do capim-elefante. Já o consumo de PB digestível aumentou em 0,04 g para cada $1 \%$ de inclusão do SACD. Este resultado indica que a adição do SACD permite maior aproveitamento da $\mathrm{PB}$ em comparação às silagens de capim elefante, mesmo com o aumento de NIDA.

Entretanto a inclusão do subproduto da acerola na ensilagem de capim-elefante se efetuada visando alterar o valor nutritivo deve levar em consideração o custo adicional de tal prática, pois as alterações são bastante sutis.

\section{Conclusão}

O subproduto da acerola desidratada pode ser incluído em até $14 \%$ na ensilagem do capim-elefante, sem comprometer o consumo e a digestibilidade dos nutrientes em ovinos, entretanto o uso fica condicionado ao custo adicional que tal prática pode acarretar.

\section{Referências}

BOLSEN, K. K. et al. Effect of silage additives on the microbial succession and fermentation process of alfafa and corn silages. Journal of Dairy Science, v. 75, n. 11, p. 3066-3083, 1992.

CÂNDIDO, M. J. D. et al. Características fermentativas e composição química de silagens de capim-elefante contendo subproduto desidratado do maracujá. Revista Brasileira de Zootecnia, v. 36, n. 05, p. 1489-1494, 2007.

CÂNDIDO, M. J. D. Qualidade e valor nutritivo de silagens de híbridos de sorgo (Sorghum bicolor (L.) Moench) sob doses crescentes de recomendação de adubação. 2000. 55 f. Dissertação (Mestrado em Zootecnia) - Universidade Federal de Viçosa, Viçosa.

COELHO, Y. S. et al. Proacerola: Programa de desenvolvimento da cultura da Acerola no Estado da Bahia. In: REUNIÃO ANUAL
DA SOCIEDADE INTERAMERICANA DE HORTICULTURA TROPICAL, 49., 2003, Fortaleza, Anais... Fortaleza: Sociedade Interamericana de Horticultura Tropical, 2003.

COMPÊNDIO Brasileiro de Alimentação Animal. São Paulo: Sidirações Rações, 1998.

CYSNE, J. R. B. et al. Composição químico-bromatológica e características fermentativas de silagens de capim-elefante contendo níveis crescentes do subproduto da graviola. Revista Ciência Agronômica, v. 37, n. 03, p. 376-380, 2006.

FERREIRA, A. C. H. Valor Nutritivo das silagens de capimelefante com diferentes níveis de subprodutos da indústria do suco de caju. 2002. 101 f. Dissertação (Mestrado em Zootecnia) - Universidade Federal do Ceará, Fortaleza.

FERREIRA, A. C. H. et al. Valor nutritivo das silagens de capim-elefante com diferentes níveis de subprodutos da indústria do suco de caju. Revista Brasileira de Zootecnia, v. 33, n. 06, p. 1380-1385, 2004.

FERREIRA, A. C. H. et al. Características químicas e fermentativas do capim-elefante ensilado com níveis crescentes de subproduto da agroindústria do caju. Ciência Animal Brasileira, v. 08, n. 04, p. 723-731, 2007.

FERREIRA, A. C. H. et al. Avaliação nutricional do subproduto da agroindústria de abacaxi como aditivo de silagem de capim-elefante. Revista Brasileira de Zootecnia, v. 38, n. 02, p. 223-229, 2009a.

FERREIRA, A. C. H. et al. Desempenho produtivo de ovinos alimentados com silagens de capim-elefante contendo subprodutos do processamento de frutas. Revista Ciência Agronômica, v. 40, n. 02, p. 315-322, 2009b.

GONÇALVES, J. S. et al. Valor nutritivo de silagens de capimelefante (Pennisetum purpureum) com adição de diferentes níveis de subprodutos do processamento de acerola (Malpighia glabra) e de goiaba (Psidium guajava). Revista Ciência Agronômica, v. 35, n. 01, p. 131-137, 2004.

JUNG, H. G.; DEETZ, D. A. Cell wall lignification and degradability. In: JUNG, H. G.,et al.. Forage cell wall structure and digestibility. Madison: American Society of Agronomy, 1993. p. 315-346.

LOUSADA JÚNIOR, J. E. et al. Consumo e digestibilidade aparente de subprodutos do processamento de frutas em ovinos. Revista Brasileira de Zootecnia, v. 34, n. 02, p. 591-161, 2005.

McCULlOUGH, M. E. Silage and silage fermentation. Feedstuffs, v. 49, n. 13, p. 49-52, 1977.

McDONALD, P. The biochemistry of silage. New York: John Willey \& Sons, 1981. 226 p.

MINSON, D. J.; WILSON, J. R. Prediction of intake as an element of forage quality. In: GEORGE, C.; FAHEY, G. C. Forage quality, evaluation, and utilization. Madison: American Society of Agronomy, 1994. p. 533-563.

MUCK, R. E. Factors influencing silage quality and their implications for management. Journal of Dairy Science, v. 71, n. 11, p. 2992-3002, 1988. 
NEIVA, J. N. M. et al. Valor nutritivo de capim-elefante enriquecidas com subproduto do processamento do maracujá. Revista Brasileira de Zootecnia, v. 35, n. 04, p. 1845-1851, 2006.

NEIVA, J. N. M.; VOLTOLINI, T.V. Produção e conservação de volumosos para reserva estratégica. In: NEIVA, A. C. G. R.; NEIVA, J. N. M. (Org.). Do campus para o campo - tecnologias para produção de leite. Fortaleza: Expressão Gráfica e Editora Ltda., 2006.

NOGUEIRA, R. J. M. C. et al. Efeito do estádio de maturação dos frutos nas características físico-químicas de acerola. Pesquisa Agropecuária Brasileira, v. 37, n. 04, p. 463-470, 2002.

QUEIROZ FILHO, J. L.; SILVA, D. S.; NASCIMENTO, I. S. Produção de matéria seca e qualidade do capim-elefante (Pennisetum purpureum Schum.) cultivar Roxo em diferentes idades de corte. Revista Brasileira de Zootecnia, v. 29, p. 69-74, 2000.

RÊGO, M. M. T. et al. Intake, nutrients digestibility and nitrogen balance of elephant grass silages with mango byproduct addition Revista Brasileira de Zootecnia, v. 39, n. 01, p. 74-80, 2010.

SÁ, C. R. L. et al. Composição bromatológica e características fermentativas de silagens de capim-elefante (Pennisetum purpureum Schum) com níveis crescentes de adição do subproduto da manga (Mangífera indica L.). Revista Ciência Agronômica, v. 38, n. 02, p. 199-203, 2007.

SILVA, J. F. C.; LEÃO, M. I. Fundamentos de nutrição dos ruminantes. Piracicaba: Livroceres, 1979. 380 p.
SILVA, D. J.; QUEIROZ, A.C. Análise de Alimentos: métodos químicos e biológicos. 2. ed. Viçosa: UFV, 2002. 165 p.

SOARES, E. C. et al. Desidratação da polpa de acerola (Malpighia emarginata D.C.) pelo processo "FOAM-MAT". Ciência e Tecnologia de Alimentos, v. 21, n. 02, p. 164-170, 2001.

STATISTICAL ANALYSIS SYSTEM (SAS). Introductory guide for personal computer's. version 7. Cary, North Carolina, USA: SAS Institute, 1990. 956 p.

TELES, M. M. et al. Consumo, digestibilidade de nutrientes e balanço de nitrogênio da silagem de capim-elefante com adição de pedúnculo de caju desidratado. Ciência Rural, v. 40, n. 02, p. 427-433, 2010.

VAN SOEST, P. J. Nutricional ecology of the ruminant. 2. ed. Cornell University Press, 1994. 476 p.

VAN SOEST, P. J.; MASON, V. C. The influence of the maillard reaction upon the nutrive value of fibrous feeds. Animal Feed Science Technology, v. 32, n. 01/03, p. 45-53, 1991.

VASCONCELOS, V. R. et al. Utilização de subprodutos da indústria frutífera na alimentação de caprinos e ovinos. EMBRAPA. 2002. (Documento, 42).

WALDO, D. R. Symposium: forage utilization by the lactating cow. Effect of forage quality on intake and forage concentrate interactions. Journal of Dairy Science, v. 69, n. 02, p. 617-631, 1986.

WILKINS, R. J. The potential digestibility of cellulose in forage and feces. Journal of Agricultural Science, v. 73, n. 01, p. 57-64, 1969. 